\title{
Analysis of Career Development of Female College Students
}

\author{
Pan Yingli \\ Ideological and Political Department Xi'an Peihua University \\ $\mathrm{Xi}$ 'an, Shaanxi Province \\ e-mail: 79255432@qq.com
}

\begin{abstract}
In recent years, with the growing popularity of higher education, college students, especially female college students' employment situation is more and more serious. The employment of female college students has aroused wide attention from all sectors of society. The employment of female college students is the result of various factors, this paper studies the problem of employment of women from the gender perspective, the current situation and reasons of the employment of female college students is analyzed. To solve the employment problem of female college students is a need for the whole society to participate in the project, only with a high sense of responsibility for female college students' employment, government, universities, employers to enhance service awareness, optimize the employment environment, broaden employment channels, breaking all the constraints of female college students' employment barriers, in order to achieve the mechanism of employment of female college students, long term system the. At the same time also to female students from their own side and strive to enhance their own capacity, change the concept of employment, enhance self-confidence and independent consciousness, cultivate active employment, entrepreneurship, and puts forward some countermeasures to solve the problem.

Keywords-Female College Students; Social Gender; Occupation Development
\end{abstract}

\section{INTRODUCTION}

Since reform and opening up 30 years of rapid economic growth of our country into a prosperous period of the history of the most vibrant, into the period of popularization of higher education Chinese. In the social transition and the market economy conditions, female college students' employment attracted much attention. Because of the characteristics of boys with different in physiological and psychological aspects, occupation development of female college students is not only common, there are personality. This raises a very real problem, namely in the education teaching practice how to many social problems and the current "for the principle of education organically combine the teaching of" how to achieve educational equity at the same time, face gender differences, gender differences on the law, the concept of innovation education and teaching content, and the training of socialist modernization needs the occupation and application of high quality, high-quality women talents.

\section{GENDER EDUCATION AND THE DEVELOPMENT OF \\ HIGHER EDUCATION}

\section{A. Gender equality education}

The principle of gender education refers to the education method should pay attention to gender differences. Equality does not mean the same as to prevent the particularity of the equality of men and women as the reason to ignore the development of girls. From our current implementation of gender equality education practice experience, more attention will be focused on the gender equality curriculum enrollment opportunity, the existence of gender bias, teaching content is gender sensitivity and gender differences in the interaction between teachers and students etc.. The education mode of 
gender equality are more for assimilation mode, defect mode instead of pluralistic mode, social justice model, attention to male and female students the same educational opportunities and resources, or education aid and compensation for the friendly face special problems for these girls, often with male education reference standard, can not shake the system the value of education established. Further lead us in the curriculum and teaching material reform into the gender perspective, often only in the male cultural center and the standard of value added under the framework of a simple model, and the deeds of outstanding female gender related topics, only to meet the Standard Specification for men only a course now, such as female scientists, women writers, women doctors, students cannot lead to look at issues from different cultural concepts, ideas and perspectives and problems.

Respect diverse experience in different regions, age, occupation, class, nationality, sexual orientation and other groups of women, in the society, culture, history, politics, economic analysis in the context of women's experience, cultural trap for female college students psychological history, reality and cognitive differences, there may be differences in personality development take the corresponding methods, education, help female college students to overcome the obstacles to success more effectively, improve the quality of talent, promote the development of female college students.

\section{B. The employment of gender culture construction}

In the process of Chinese social transformation, gender culture construction in the field of employment and promote the change of gender culture, but also counterproductive in economic reform and economic development. On the one hand, gender equality and gender to participate in social economic activities has been widely accepted; on the other hand, participation in social and economic activities in the process of society has different expectations of gender, sexual behavior, showing different habits and tastes and preferences, women compared with men is still in a weak position in the field of employment. The reason, regardless of individual employment and occupation choice is the external social environment, are permeated with the employment impact of gender culture.

\section{GENDER AND EMPLOYMENT OF COLLEGE TUDENTS}

\section{A. The employment problem of female college students}

At present, the employment problem of college students have been exposed to some aspects of the education system, professional structure, employment system, employment policy, labor market construction and other issues. These problems are exacerbated by the severity of the employment situation of college students, and the employment of female college students is more difficult. One is the overall level of education of women than men, statistics show that women of new higher education opportunities are more concentrated in college level; two is the professional female choice is narrow, mostly choose literature, law and economics and society to provide professional, and these major related jobs and no significant increase; the three is sex. Discrimination. In the process of recruiting civil servants and staff of public institutions in some countries, government departments, institutions and state-owned large and medium-sized enterprises do not comply with the basic national policy of gender equality and the equality of employment law; four is the occupation limit. In the recruitment process, many occupation have been labeled gender labels, such as senior managers, technical director and other positions were posted on male job labels; secretarial service personnel, and was attached to the female post label, artificially created sex segregation.

In addition to the constraints of objective led to female employment difficulties, from a subjective point of view:

\section{1) The concept of career lag}

In the era of the planned economy, college means "transition and identity, glorify and illuminate the ancestors" is "God's favored one" instead of "commoner" employment by the state "uniform distribution", and "when the cadres", no competition and no employment now hidden gender discrimination, safety, stable and strong the collective sense of belonging and sense of honor, now, this pattern of employment has gone for ever, 
self employment, two-way choice, is the current and future employment trends and the mainstream, but some girls can not change over time, the traditional employment mode of thinking is still deep-rooted, entrenched in the mind, the blind pursuit of employment occupation prestige, excessively regardless of the nature of the unit, working environment and personal identity, self occupation no face, no guarantee to the new economic organization, operation, practice, service of The work of dignity, a desire to enjoy lifelong employment, lack of awareness of multiple employment; once the job is blaming setback, no way, no major Born Under A Bad Sign, sought after, many employment opportunities in this hesitation in lost.

\section{2) The concept of employment dislocation}

In the unrealistic, not appropriate self-esteem and self-confidence, employment expectations are too high or too low, can not objectively analyze themselves and society. In the face of unavoidable employment competition, some of the girls agree with social prejudice against women, a strong sense of inferiority, overcautious, cowardice, lack of self promotion of courage, when job seekers "bodyguards" accompanied by shilly-shally decisions, difficult to obtain the employer trust; some even dare not to negotiate with the recruitment unit, dull job interview once a formality, failure is nothing, for a long time to walk out of the shadow of inferiority, depression and confusion, become more confident; overestimate yourself is exaggerated self strength, the employment expectation is too high, to the center of the city and the high salary will be "white collar" and disdain for the "blue collar", ambitious in rural areas; students generally have the girls jump out "farming door" to change the identity of the idea of wandering in the city after graduation would also not return to backward but needs to know Knowledge and cultural homeland; or serious vanity, and strong students compete, underachievement, selectivity, thereby artificially narrowing employment space.

\section{3) Insist on social justice}

"Gender equality is a basic national policy of our country, women and men enjoy equal employment and the basic content of employment rights is also China's labor regulations, but the traditional culture of gender discrimination still exists in the workplace and society today, openly not girls, the same conditions to male not female. Or artificially raise the female college students' employment threshold," sex "this is not the people's will transfer things become the employment of female college students encounter the first obstacle. According to the Jiangsu Provincial women's Federation: 55.5\% in the employment of female college students suffered employment discrimination. The social environment for female college students hate sex discrimination, particularly eager men and women can participate in the competition on the basis of equality, it is perfectly logical and reasonable, and it will become the trend of social development, but the formation of this phenomenon is the result of a long history of cultural heritage, it also can eliminate the non overnight, if blindly demanding society justice and fairness, and to think that the world is surging anger not yet appeased, however, exaggerate the dark side, negative light, it will form a very rational mentality of employment, employment will be due to the road is long and bumpy.

\section{COUNTERMEASURES OF IMPROVING FEMALE} COLLEGE STUDENTS' EMPLOYMENT DIFFICULTIES

\section{A. Female college students enhance occupation} accomplishment, the courage to accept the challenge

1) To understand their own interests and personalities, clear occupation development goals and direction.

With the help of the school under the guidance of college students need to gradually recognize self from the beginning, to find and understand their own character, interest and expertise, and to plan for their own professional, clear direction and goals of development, so as to carry on the reasonable occupation career planning and occupation orientation, effectively guide the future employment.

2) Analysis of the employment situation, the employment pressure and maintain a moderate sense of employment anxiety. 
The graduates should gradually contact and understand the current employment situation, the employment situation clearly, to enhance the sense of crisis and competition, consciously from improving their employment ability, improve their quality and prepare for employment and work hard. "The level of no-preparation", for the employment situation and should fully understand the psychological preparation, can continue to be confident when looking for a job, face the social choice, and actively participate in market competition.

3) Crrectly treat the success of job seekers to establish a scientific concept of frustration.

The current employment situation, job frustration often become. Female college students should face gender discrimination and employment pressure, enhance the competitive strength and confidence. Female college students will encounter gender discrimination often in the job, as many employers in the recruitment has made it clear that as long as the boys "or" under the same conditions as the boys first ", this phenomenon leads to female college students employment pressure is relatively large, more low employment confidence. Today's college students employment direction gradually showing a trend of diversification, professional counterparts are no longer absolute employment standards, but is still the main influencing factors of employment. So, in college, female college students face positive attitude with their own professional learning; in the course of employment, should establish a correct concept of employment, to play their own advantages, change people's psychological bias; in psychology to have self-confidence, dare to compete, to overcome the bad psychological state of inferiority, timid in the post occupation; be confident, self-improvement, overcome the dependence; only by their own strength to change the prejudices of society, so as to gain social identity and realize their own value.

\section{B. The implementation of sex education in Colleges and} universities, strengthen employment guidance

1) Sex education in Colleges and universities should focus on the cultivation of the consciousness of self development of female college students, meet the internal demand of their development. The female college students' occupation ability construction and school curriculum construction combination, such as the creation of relevant terminological course: Marx's view of women, female college students, female college students' occupation career guidance, female occupation image design and modern etiquette, etc.. To strengthen the construction of the theoretical study of female college students.

2) Reasonable Occupation Expectation and positioning, establish a scientific concept of employment. The formation of reasonable employment outlook will not happen overnight, but a gradual process. Therefore, combined with the occupation education, through publicity and education of employment and employment policy guidance and mobilization, to enable students to gradually establish a popular concept of choice; based on reality, reasonable Occupation Expectation and positioning, and continue to strengthen their own business and service in the employment consciousness; should recognize that no matter how the situation is grim, more rational cognition and the choice will be more of a hope of success.

3) Employment psychological counseling, improve the occupation planning ability. The school employment guidance should give them special attention to and guidance: to help them eliminate its role of women and discrimination of vulnerable groups' sense of inferiority, encourage them to dare; to participate in the competition in an equal, positive, confident, challenge the mind; to help them with their own characteristics of reasonable occupation orientation; to encourage them to redouble their efforts from all aspects of development and self-improvement, enhance their employment competitiveness; to eliminate gender discrimination to appeal to the community, giving women equal employment rights and opportunities.

As the basic training of female college students' occupation ability of ascension; the concept of using the methods of social work, the growing group of female college students occupation ability as the specific way of 
making detailed, the team plans to evaluate the intervention effect of the intervention, constantly sum up experience; by providing mental health education on female college students' personalized counseling, type of occupation ability promotion advisory services; to create a platform and practice base, increasing female college students work experience, training, labor employment experience and frustration experience; according to the characteristics of female students in different grades, occupation ability construction research training program..

C. The social level: The law and public opinion-—Support

There is no gender discrimination legislation through the establishment of policy. Except for special industries, less than $50 \%$ of female employment rates for employers, increase fertility fund, endowment insurance and related project amount, to encourage employers to employ women. If a woman met the employer rejected on grounds of sex, use the law to protect their rights, legal workers, hope the relevant government departments and women's organizations to provide protection and assistance for female graduates. Government departments and personnel organization recommended the development of effective measures for supervision and intervention on all issues of gender discrimination, female education and employment and safeguard the rights and interests of the labor remuneration.

The whole society should establish the social value of family. To improve the existing welfare system, to establish the social value of the national policy of family, and develop with the support of the social security system.
The government can provide government loans to more female workers of the department or government subsidies, the proportion of the amount of tax and hook or unit of the female workers. The employer should correct the concept of gender discrimination and improve the college girls in the objective environment, give them equal rights in employment, development.

In addition, the mass media has a great influence on the formation of the concept of gender, the audience so to play the guiding function and education function of mass media and social gender culture, media workers should consciously examine gender concept of their own, take the initiative to accept the theory of social gender training.

\section{ACKNOWLEDGMENT}

Research on the training mechanism of College Students' career planning in the perspective of social gender from the 2016 annual reform project of Xi'an Peihua University (PHY1630)

\section{REFERENCE}

[1] Qing Mei Meng. Contemporary social differences and the equal opportunities of adult education in China [J]. Vocational Education Newsletter, 2007 issue third

[2] Tang Yahui.On educational policy and gender equality[J]. Journal of Hunan Administrative College (Bimonthly) 2007 issue fifth

[3] Huijuan Zhao. Four orientations of gender difference research [J]. Journal of Southwestern Normal University (HUMANITIES AND SOCIAL SCIENCES EDITION), 2003(5)

[4] Liu ru1.Androgyny and the change of female gender roles [J]. Journal of Chongqing University of Science and Technology (SOCIAL SCIENCES EDITION)) 2008 issue first 